\title{
The use of hypnosis in gastroscopy: a comparison with intravenous sedation
}

\author{
Philip Conlong, Wynne Rees
}

\begin{abstract}
Summary
A total of 124 subjects who were undergoing routine endoscopy were randomly assigned to one of three groups. All three groups received lignocaine throat spray. The first group additionally received midazolam, the second received hypnosis, whilst the third only received lignocaine throat spray. Although hypnotised patients were deemed by an independent observer to be less agitated than the other two groups $(p<0.03)$, they reported the gastroscopy to be significantly more uncomfortable $(p<0.042)$ and scored higher in their memory for the procedure $(p<0.001)$. They also took slightly longer to induce than the midazolam group. The midazolam group on the other hand rated the procedure as significantly more comfortable although paradoxically were seen by an independent observer as being more agitated. They were also significantly more amnesic. The endoscopist encountered more procedural difficulties with this group but this did not reach levels of significance. Hypnosis was not shown to be an effective alternative to intravenous sedation in gastroscopy.
\end{abstract}

Keywords: hypnosis; gastroscopy; sedation; midazolam

Short-acting benzodiazepines can cause significant morbidity and mortality. Cardiorespiratory problems account for $50 \%$ of the morbidity and $60 \%$ of deaths following endoscopy. ${ }^{1-9}$ Most endoscopists use sedation ${ }^{2}$ although an increasing number offer the alternative option of avoiding it altogether with obvious benefits to the patient, including quicker recovery times and reduced time off work. With these thoughts in mind we wanted to investigate the possibility of using a different approach to sedation.

Although hypnosis has been used in dental Hope Hospital, Eccles Old Road, Salford, Manchester M6 8HD, UK

P Conlong

W Rees

Correspondence to P Conlong, 14 Lidgate Grove, Didsbury,

Manchester M20 6TS, UK

Accepted 9 October 1998 apparent advantage over and above a lignocaine throat spray.

\section{Methods}

A total of 124 patients were recruited from patients needing a diagnostic gastroscopy at the Royal Oldham Hospital in Manchester. The study group comprised 72 males and 52 females with an average age of 58 years (range 19-92). The study was approved by the local ethics committee.

Patients were randomised to one of three groups, all of which received lignocaine throat spray. Group 1 also received midazolam, group 2 received hypnosis, and group 3 only had the lignocaine throat spray. Nine patients were excluded; seven who could not understand the instructions or complete the questionnaire and two with unstable angina. Of the remaining patients, 45 had cardiorespiratory problems requiring medication; 18 of these had chronic obstructive pulmonary disease, 16 had angina, five had suffered myocardial infarcts more than 6 months previously and six had asthma. There were 46 patients in the sedation group (24 men), 45 in the lignocaine group (20 men) and 33 in the hypnosis group (13 men).

Following randomisation to these groups the patients were then randomly assigned to positions on a busy gastroscopy list with an average of 10 patients per session. The procedure was explained to them by a nurse who also explained the nature of the grouping to which they had been allocated.

The doctor carrying out the hypnosis was fully trained in the technique. All patients were taken individually into a separate anteroom next to the endoscopy suite. They all had a venflon inserted and lignocaine spray to the hypopharynx. The midazolam group were then sedated by titrating the dose to produce ptosis and drowsiness. Those having hypnosis were induced by one of the authors, using a fixation technique. This involved looking at a blue light from a spotlight directed onto a wall opposite the patient. The hypnotist was allowed $5 \mathrm{~min}$ utes from the time the venflon was inserted to adequately hypnotise the patient. This was assessed by a nurse present in the room. A breathing technique was then used to induce a progressively deeper hypnotic state. This involved giving suggestions to the patient of increasing drowsiness and heaviness of the eyes whilst slowly counting to 20 in time with inspiration. The patient was then asked to close their eyes. Further suggestions were given to the patient to produce increasing drowsiness. The hypnotist used the onset of a deeper respiratory pattern and the development of changes 
Table 1 Comparison of group scores

\begin{tabular}{llll}
\hline & Hypnosis $(n=33)$ & Sedation $(n=46)$ & Lignocaine $(n=45)$ \\
\hline Mean level of agitation ${ }^{\star}$ & 1.57 & 2.14 & 2.30 \\
Mean time for induction (min,s) & 4,52 & 4,0 & - \\
$\quad$ Range & $3,10-5,10$ & $3,20-4,12$ & 8,36 \\
Mean time for gastroscopy (min,s) & 9,25 & 8,27 & 34 \\
Oxygen saturation $(n>95 \%)$ & 27 & 32 & 10 \\
Difficult gastroscopies $(n)$ & 3 & 12 & 3.65 \\
Mean level of discomfort & 3.57 & $2.9^{\star}$ & 45 \\
Full recall of the gastroscopy $(n)$ & 28 & $27^{\star}$ & \\
\hline
\end{tabular}

$\star$ Significant result, $\mathrm{p}<0.05$.
Table 2 Diagnoses

\begin{tabular}{llll}
\hline Group & $\begin{array}{l}\text { Hypnosis } \\
(n=33)\end{array}$ & $\begin{array}{l}\text { Sedation } \\
(n=46)\end{array}$ & $\begin{array}{l}\text { Lignocaine } \\
(n=45)\end{array}$ \\
\hline $\begin{array}{l}\text { Gastritis } \\
\text { Oesophagitis }\end{array}$ & 12 & 21 & 23 \\
$\quad$ Mild/mod & 2 & 1 & 2 \\
$\quad \begin{array}{l}\text { Severe } \\
\text { Peptic ulcer disease }\end{array}$ & - & 2 & - \\
Carcinoma & 3 & 2 & - \\
Normal & 12 & 2 & - \\
\hline
\end{tabular}

$\min 25 \mathrm{~s}$, the sedated group $8 \min 27 \mathrm{~s}$, and the lignocaine group $8 \mathrm{~min} 36 \mathrm{~s}$.

No significant differences were found in oxygen saturation. It was satisfactory (ie, at least $95 \%$ ) in $27 \%$ of the hypnotised group, $32 \%$ of the sedated group and $34 \%$ of the lignocaine group. Most of the patients who had an unsatisfactory oxygen saturation developed this at intubation. Although there were differences between the groups in the number of difficult endoscopies, these did not reach levels of significance. There were problems with three patients in the hypnotised group; 12 in the sedated group, and 10 in the non-sedated group. The vast majority of these problems were intubation-related.

There was a significant difference in levels of comfort ratings between the three groups. The sedation group scoring significantly better (2.90) than the hypnosis group (3.57) or the lignocaine throat spray group $(3.65)(\mathrm{p}<0.042$, ANOVAR). There were no significant differences between the latter two groups.

A significantly smaller number of sedated patients (27) had full recall of the gastroscopy compared to the hypnotised group (28) and the lignocaine group $(45)\left(\mathrm{p}<0.001, \chi^{2}\right)$. There were no significant differences in the abnormalities found at gastroscopy between the three groups (table 2).

\section{Discussion}

The group receiving midazolam outscored the hypnosis group in reported levels of comfort for the procedure, the degree of amnesia, and the time taken for induction, the first two items reaching statistical significance. They only did poorly on two measures: the number of patients having a less than satisfactory oxygen saturation, and those that had a difficult endoscopy, although neither of these reached statistical significance.

The hypnosis group performed similarly to the lignocaine throat spray group, only managing to score significantly better in the nurse's score of levels of agitation during the procedure. This seems at odds with most of the patients' reports of poor levels of comfort for the procedure. It also took slightly longer for the hypnotist to achieve what he thought was a hypnotised state in comparison to midazolam. The endoscopist, however, reported less difficulty with the endoscopy in this group, although there was no statistically significant difference compared to the other two groups. The hypnotised group scored only slightly better that the lignocaine throat spray group on
There were no significant differences in the total time taken for the gastroscopy; with hypnotised group completed in an average of 9 
amnesia for the procedure, and considerably worse than those receiving midazolam.

There would seem to be two ways to interpret the apparent failure of the hypnosis group. Firstly, it is possible that most of the patients were not in the required hypnotic state. In the limited time available to hypnotise the patient prior to gastroscopy, some may simply have been relaxed. This would explain the very good scoring on the agitation scale assessed by the nurses in the endoscopy unit, the relative ease of the gastroscopies in this group, the fact that only some of the patients achieved amnesia for the procedure, and the higher subjective levels of discomfort. An alternative hypothesis is that hypnosis simply does not work at all and that patients in this group were all just acting what they assumed would be a hypnotic state, therefore producing only marginally better scores than the group receiving only lignocaine.

Reviewing the evidence on hypnosis, there are several studies that suggest it is of use across a broad range of specialties. ${ }^{10-15}$ If one accepts the premise that hypnosis works, albeit that the

1 Daneshmend TK, Logan RFA, Bell GD. Sedation for upper GI endoscopy. Gut 1991;32:2-15.

2 Bell GD, McCloy RF, Charlton JE, Campbell F. Recommendations for standards of sedation and monitoring during endoscopy. Gut 1991;32:823-7.

3 Solomon SA, Kajla V, Bannerjee A. Can the elderly tolerate endoscopy without sedation. $\mathcal{F} R$ Coll Physicians Lond 1994 28:1-5.

4 Quine MA, Bell GD, McCloy RF, Charlton JE, Devlin MB, Hopkins A. Prospective audit of upper GI endoscopy in the regions of England: safety, staffing and sedation methods. Gut 1995;36:462-7.

5 Cotton PB, Williams CB. Practical GI endoscopy, 3rd edn. Oxford: Blackwell, 1990; pp 52.

6 Carey WD. Indications, contraindications and complications of upper GI endoscopy. In: Sivall MV, ed, Gastroenterotions of upper GI endoscopy. In: Sivall MV, ed, Gastroenterological endoscopy

7 Hart R, Classen M. Complications of diagnostic gastrointestinal endoscopy. Endoscopy 1990;22:229-33.

8 Bell GD. Premedications and intravenous sedation for gastrointestinal endoscopy. Aliment Pharmacol Ther 1990;4 103-22. mechanisms involved are unclear, then one has to ask what happened in this study. The most likely explanation is that the hypnotist did not have enough time to produce a hypnotic state in all the patients. Judging depth of hypnosis is difficult and one weakness of this study is that we did not ask the hypnotist afterwards to assess his satisfaction with this in each subject prior to the gastroscopy. One improvement to the study design would be to allow more time for hypnosis. This would make it easier to carry out accepted tests on the adequacy of hypnosis such as changes in sensory perception. This of course begs the question of how useful hypnosis would be on a busy endoscopy list. If one could conclusively show that it worked, it might well have a use in patients with cardiorespiratory disease in whom the risks of using benzodiazepines are higher.

In conclusion, we have not found hypnosis to be of value in gastroscopy, although this may have been because the hypnotist did not have enough time available to induce the patient fully.
9 Fliesher D. Monitoring the patient receiving sedation for gastrointestinal endoscopy, issues and guidelines. Gastrointest Endosc 1989;35:262-6.

10 Meurisse M, Faymonville ME, Joris J, Nyuyen Dang D, Defechereux T, Kamoir E. Endocrine surgery by hypnosis from fiction to daily clinical applications. Ann Endocrinol 1996;57:494-501.

11 Ashton C, Whitworth GC, Selmonridge JA, et al. Self hypnosis reduces anxiety following coronary artery bypass surgery. A prospective randomised trial. F Cardiovasc Surg 1997;38:69-75.

12 Enquist B, Fisher K. Pre-operative hypnotic techniques reduce consumption of analgesics after surgical removal of third mandibular molar: a brief communication. Int $\mathcal{f}$ Clin Exp Hypn 1997;45:102-8.

13 Golan HP. The use of hypnosis in the treatment of psychogenic oral pain. Am f Clin Hypn 1997;40:89-96.

14 Giri T, Mainland P, Chan MTV, Short TG. Decreased thioGiri T, Mainland P, Chan MTV, Short TG. Decreased thio-
pental requirements in early pregnancy. Anaesthesiology pental require

15 Schultz-Stubner S. Hypnosis - an alternative to sedatives without side effects during regional anaesthesia. Anaesthetist 1996;45:965-9. 


\title{
Mature bone metaplasia in abdominal wall scar
}

\author{
R A Daoud, M J Watkins, G Brown, N Carr
}

\begin{abstract}
Summary
A 58-year-old man who had had three laparotomies for gastric surgery, developed a painful mass in the abdominal wall scar. Radiology confirmed bone formation in the scar. The bone was excised and the wound repaired. Histology confirmed metaplastic mature bone formation. This case draws the attention to the clinical condition of bone formation in midline scars. Clinically, it should be differentiated from scar recurrence following surgery for abdominal malignancy.
\end{abstract}

Keywords: myositis ossificans; heterotopic ossification

A 58-year-man presented with a 9-month history of a painful swelling in a left paramedian scar. In 1966, he had a Polya gastrectomy, for peptic ulcer disease. In 1993, he presented with severe biliary reflux oesophagitis. Upper endoscopy confirmed the diagnosis. He was treated with omeprazole and cisapride with little improvement. He was referred for surgical opinion and in 1996, he had a 'Roux en y' reconstruction. This was followed 8 weeks later by laparotomy for division of omental adhesions causing jejunal obstruction. On this third laparotomy, ectopic calcifications were noted in the scar. Postoperatively, he developed a wound infection followed by a small bowel fistula, which closed spontaneously.

In 1997, he presented with a tender mass under the laparotomy scar. Initially, ultrasound and magnetic resonance imaging (MRI) confirmed a soft tissue mass. The pain in the scar increased gradually over the next few months, and surgical exploration of the mass was indicated. A pre-operative plain X-ray showed abdominal wall calcifications.

At operation, a $140 \times 45 \mathrm{~mm}$ piece of mature bone was found underneath the scar, between the posterior rectus sheath and the peritoneum. This was dissected and was found to merge with the xiphoid cartilage. The bone was divided just below the lower end of the sternum using a bone-cutting forceps.

\section{Histology}

Macroscopically, the specimen was a hard spindle-shaped piece of tissue $140 \times 45 \times 20$ $\mathrm{mm}$, which required sawing and blocks were decalcified. Microscopically, the lesion consisted of mature lamellar bone within which bone marrow showing trilineage haematopoiesis was present, together with cartilage and fibro-fatty connective tissue. The histological

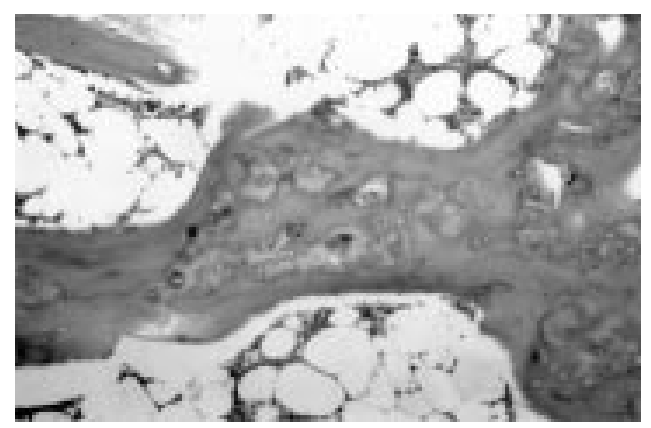

Figure Photomicrograph showing bone and bone marrow. Within the bone, areas of cartilage are visible. (Haematoxylin and Eosin, original magnification $\times 50$ )

features were unlike those of myositis ossificans, and the appearance was most in keeping with osteocartilaginous metaplasia. There was no cellular atypia or evidence of malignancy.

\section{Discussion}

Traumatic myositis ossificans has been repeatedly reported in the literature. This usually follows a contusion to a muscle caused by a sport injury. ${ }^{1}$ In midline incisions, injury to the xiphoid process or pubis may liberate boneforming cells. ${ }^{2}$ As in this reported case, the initial clinical picture is often confused with that of osteomyelitis or soft tissue abscess. ${ }^{3}$ A case of myositis ossificans was also reported in the platysma following radical neck dissection. ${ }^{4}$ In second-look surgery for intra-abdominal malignancy, bone formation should not be mistaken for recurrent malignant disease in the abdominal wall. ${ }^{2}$

A palpable mass with severe loss of movement is the usual clinical presentation. X-Rays later show a fluffy density in soft tissue, and ultrasound may sometimes show evidence of the condition within a week after trauma. ${ }^{1}$ Computed tomography (CT) scan can show complete ossifications indicative of the mature phase of the pathologic process and may help in planning surgical resection. ${ }^{5}$ In our case MRI was used instead of CT scan.

Surgical removal of the calcified swelling is often indicated due to increasing pain and disability. ${ }^{3}$ In case of athletes, a large mass of mature lamellar bone is also associated with muscle weakness and significant loss of joint motion. ${ }^{6}$ Shugar warns that recurrence may follow excision of the abnormal bone, and recommends surgery only if there are significant symptoms associated with the lesion. 
Disodium etidronate has been claimed to delay and partially prevent postoperative recurrence of heterotropic ossification.?

The immature bone, cellular proliferation and zoning characteristic of myositis ossificans were absent. ${ }^{8}$ In the histological differential diagnosis we considered a neoplasm of the xiphoid with which the lesion appears to be in continuity. However, the lack of immature or atypical elements was more in keeping with a metaplastic phenomenon. An osteochondroma consists of bone and cartilage, but typically has a cartilaginous cap with bone beneath. ${ }^{9}$ In our patient, the cartilage and bone were mixed

1 Kaeding CC, Sanko WA, Fischer RA. Myositis ossificans. Physician Sportsmed 1995;23:77-82.

Marteinsson BT, Musgrove JE. Heterotopic bone formation in abdominal incisions. Am $\mathcal{F}$ Surg 1975;130:23-5.

3 Jenny P, Spescha H, Fliegel C. Zur Myositis Ossificans circumscripta. Z Kinderchirurg 1982;35:86-7.

4 Shugar MA, Weber AL, Mulvaney TJ. Myositis ossifican following radical neck dissection. Ann Otol Rhinol Laryngol 1981;90:169-71.

5 Amendola MA, Glazer GM, Agha FP, Francis IR, Weatherbee L, Martel W. Myositis ossificans circumscripta: computed tomographic diagnosis. Radiology 1983;149:7759.

6 Lipscomb AB, Thomas ED, Johnston RK. Treatment of myositis ossificans traumatica in atheletes. Am $\mathcal{F}$ Sports Med 1976;4:111-20. together, with no cap-like structure. Bizarre parosteal osteochondromatous proliferation was also considered, but this tends to occur in the hands and feet, and no bizarre chondrocytes were present. ${ }^{10}$

We have here described a case of metaplastic bone formation with marrow spaces and cartilage in an extraskeletal site. The condition must be considered in swellings affecting midline abdominal scars.

We would like to thank the Imperial Cancer Research Fund Histopathology Unit for reviewing the histology.

7 Stover SL, Niemann KM, Miller JM. Disodium etidronate in the prevention of postoperative recurrence of heterotropic ossification in spinal-cord injury patients. F Bone ft Surg (Am) 1976;58:683-8.

8 Sumiyoshi K, Tsuneyoshi M, Enjoji M. Myositis ossificans. A clinicopathologic study of 21 cases. Acta Pathol fpn 1985; 35:1109-22.

9 Rosai J. Bones and joints. In: Rosai J, ed. Ackerman's Surgical pathology, 8th edn. St Louis: Mosby, 1996; pp 1917-2019.

10 Nora FE, Dahlin DC, Beaubout JW. Bizarre parosteal osteochondromatous proliferations of the hands and feet. Am F Surg Pathol 1983;7:245-50.

\title{
High-altitude illness induced by tooth root infection
}

\author{
J Finsterer
}

\begin{abstract}
Summary
High-altitude illness may occur after recent pulmonary infection, but highaltitude illness after root canal therapy has not been described previously. A 44-year-old man is presented who skied to a $3333 \mathrm{~m}$ high peak in the Eastern Alps one day after he had undergone root canal therapy because of a tooth root infection. After 4 hours above $3000 \mathrm{~m}$ severe symptoms of high-altitude illness, including pulmonary oedema, developed. His condition improved after immediate descent. The next day he presented with local and general signs of infection which were successfully treated with gingival incisions and antibiotics. In conclusion, acute tooth root infection and root canal therapy may induce high-altitude illness at an altitude just above $3000 \mathrm{~m}$.
\end{abstract}

NKH Rosenhügel, Vienna, Austria J Finsterer

Correspondence to Dr J Finsterer, Postfach 348, 1180 Wien, Austria

Accepted 2 September 1998
Keywords: high-altitude illness; pulmonary oedema; root canal therapy; tooth root infection

Usually, high-altitude illness occurs at elevations $>2500 \mathrm{~m}$ and includes mountain sickness, high-altitude pulmonary oedema, cerebral oedema and retinal haemorrhage. ${ }^{1}$
Whether or not recent infection predisposes to high-altitude illness is controversial. ${ }^{2}{ }^{3}$ Highaltitude illness associated with tooth root infection, as in the following case, has not been reported previously.

\section{Case report}

Four weeks before a skiing trip, a previously fit 44-year-old man experienced increasing fatigue and declining fitness. There was no indication of an infectious disease, although root canal therapy for a granuloma of the first left upper incisor had been proposed by the treating dentist 2 month earlier but declined by the patient. Two weeks before the trip, the patient experienced aching of the first left upper incisor with an associated gingival inflammation over its root column. Radiography was indicative of tooth canal infection, and the patient underwent root canal therapy, leaving the root canal open, one day before starting his skiing trip.

After slowly ascending to $1720 \mathrm{~m}$ by bus, he took a cable car to reach $3170 \mathrm{~m}$ within one hour. He had ascended to altitudes $>3000 \mathrm{~m}$ within one day without major problems several times before. This time he observed unusual 
breathlessness and fatigue when ascending to $3333 \mathrm{~m}$, prompting him to take a rest every few steps. Despite taking an unusual 2 hours to reach the summit and return, and despite persisting symptoms, he set out to climb another nearby peak, but dyspnoea and tiredness forced him to abandon this attempt. Though he was trained as a skiing teacher, he moved like a beginner, could hardly stay on the lift, and had to take several rests before descending to 2900 $\mathrm{m}$. When skiing further down, the frequency of pauses increased and his breathing failed to return to normal. Disorientation and nausea occurred. After trying to descend further, he fell and could not get up. He started to lose consciousness and recognised paresthesias in both arms and legs. He managed to attract the attention of a passing physician to whom he presented with drowsiness, severe dyspnoea, tachypnoea, coughing, cyanosis and tachycardia. Though auscultation was not possible in this acute situation, the physician suspected high-altitude oedema and organised an immediate transfer to an altitude of $2300 \mathrm{~m}$ with a snow-tending machine. There the patient's condition markedly improved, but he was not able to walk unaided before reaching $1720 \mathrm{~m}$.

During the following night, a gingival abscess developed. Blood chemistry the next day revealed a leucocytosis of $11.9 \mathrm{~g} / 1$ (normal 4-10 g/1), C-reactive protein $9.0 \mathrm{mg} / 1(0-5$ $\mathrm{mg} / \mathrm{l})$ and serum creatine kinase $300 \mathrm{U} / 1(0-72$ $\mathrm{g} / \mathrm{l}$ ) with normal MB-fraction. Blood culture was negative and chest X-ray and electrocardiogram were normal. The tooth infection was successfully treated by repeated gingival incisions and clindamycin for 8 days.

\section{Discussion}

The pathophysiological background of highaltitude pulmonary oedema is poorly understood. One theory proposes primary cerebral hypoxia causing cerebral vasodilatation, elevated cerebral capillary pressure and increased sympathetic response. ${ }^{4}$ Another theory is based on the assumption that, due to the low $\mathrm{pO}_{2}$ at high altitude, liquid may penetrate into

1 Murdoch DR. Symptoms of infection and altitude sickness mong hikers in the Mount Everest region of Nepal. Aviat Space Environ Med 1995;66:148-51.

2 Brandt S, Brugge $\mathrm{H}$. High-altitude pulmonary oedema in the eastern alps. Wien Klin Wochenschr 1994:106:742-5

3 Hacket PH, Roach RC. High altitude pulmonary oedema. $\mathcal{F}$ Wilderness Med 1980;1:3-26. the alveolar cave. Respiratory infection, impairing oxygen uptake and reducing oxygen delivery at the tissue level, may have an additional effect. ${ }^{1}$ The release of vasoactive, inflammatory mediators during infection may directly aggravate high-altitude illness. ${ }^{1}$ There are limited and controversial data on the relationship between recent infection and the occurrence of high-altitude illness. ${ }^{1}$ Pneumonia and mediastinitis have been reported to predispose to high-altitude illness, ${ }^{1}{ }^{2}$ although upper respiratory tract infection does not. ${ }^{5}$ Whether or not predisposition to high-altitude illness increases with the severity of infection or is dependent on the type of infection, remain to be determined.

The present case is interesting because of the relatively low altitude at which high-altitude illness developed and the rapidity with which the symptoms occurred. Slight symptoms occurred immediately after reaching $3170 \mathrm{~m}$ and progressed to pulmonary oedema after only 4 hours above $3000 \mathrm{~m}$. Usually, there is a constant delay between arrival at high altitude and the onset of symptoms of high-altitude illness. ${ }^{1}$ In our patient, the occurrence of highaltitude illness at a relatively low altitude and the quick development of pulmonary oedema were assumed to be due to inflammatory mediators of the tooth root infection, the effect of the root canal therapy, or the incipient gingival abscess. An unrecognised pre-existing illness as a possible explanation for the altitude illness is rather unlikely, since the patient completely recovered after the gingival incisions and clindamycin therapy and follow-up clinical and laboratory investigations were all normal. A further argument for the infection as the most probable cause of the high-altitude illness is the fact that he had not experienced any similar problems during previous trips to $>3000 \mathrm{~m}$. Disregarding the cause of highaltitude illness, the treatment of choice remains the immediate descent to lower altitudes. ${ }^{6}$

In conclusion, tooth root infection and root canal therapy may predispose to high-altitude oedema. Such patients should not climb mountains $>3000 \mathrm{~m}$ before full recovery.

4 Krasney JA. A neurogenic basis for acute altitude illness. Med Sci Sports Exerc 1994;26:195-208.

5 Torrington HG. Recurrant high-altitude illness associated with right pulmonary artery occlusion from granulomatous mediastinitis. Chest 1989;96:1422-3.

6 Hackett PH, Roach RC. Medical therapy of altitude illness. Ann Emerg Med 1987;16:980-6. 


\title{
Gynaecomastia as a presenting feature of thyrotoxicosis
}

\author{
W B Chan, V T F Yeung, C C Chow, W Y So, C S Cockram
}

\begin{abstract}
Summary
The association between gynaecomastia and thyrotoxicosis is well recognised. However, the reported frequency of the association is variable, partly depending upon the defining criteria used. Here we report two patients with thyrotoxicosis in whom gynaecomastia was the presenting feature. Both patients had other contributing factors, which are assumed to have predisposed to gynaecomastia. In both patients, the gynaecomastia resolved with successful treatment of the thyrotoxicosis. When gynaecomastia is a presenting, or prominent feature of thyrotoxicosis, the possibility of additional underlying pathology should be considered.
\end{abstract}

Keywords: gynaecomastia; thyrotoxicosis; sex hormone

Gynaecomastia has long been known to be associated with thyrotoxicosis but does not usually occur as a presenting feature of the condition. Its reported frequency was as high as $40 \%$ in two early series. ${ }^{12}$ However, recent reviews suggest a much lower frequency than previously thought. ${ }^{3}$ Differences in reported frequency depend in part upon the criteria used for defining the presence of gynaecomastia.

Here we report two patients with thyrotoxicosis in whom gynaecomastia was the initial presenting feature. Subsequent investigations showed that there were other co-existing factors in both patients to explain the development of gynaecomastia.

\section{Case reports}

Case 1

A 30-year-old Chinese man presented to his general practitioner because of left-sided gynaecomastia with galactorrhoea, associated with decreased libido and sexual potency for 6 months. He was referred for further investigation. His wife was pregnant at 8 weeks gestation. There was no history of drug intake. There were no symptoms of thyrotoxicosis. Physical examination confirmed left-sided gynaecomastia and galactorrhoea. Secondary sexual characteristics, testis, fundi and visual fields were all normal. A small soft goitre was palpable. Initial investigations showed that he was biochemically thyrotoxic with serum sensitive thyroid stimulating hormone $(\mathrm{sTSH})<$ $0.03 \mathrm{mIU} / 1$ (normal range: $0.3-4 \mathrm{mIU} / 1$ ), and free thyroxine $\left(\mathrm{T}_{4}\right) 22.9 \mathrm{pmol} / 1$ (10.2-19.6).
Anti thyroglobulin and anti thyroid microsomal antibodies were negative. The prolactin concentration was elevated at $1320 \mathrm{mIU} / 1$ $(<480)$. Follicle-stimulating hormone $(\mathrm{FSH})$ was $2.4 \mathrm{IU} / 1(<12)$, luteinising hormone $(\mathrm{LH})$ $3.5 \mathrm{IU} / 1(<15)$, and testosterone $5.9 \mathrm{nmol} / 1$ (12.0-34.0), indicating hypogonadotrophic hypogonadism. Oestradiol concentration was 112 pmol/1 (<361). Sex hormone binding globulin (SHBG) was $15 \mathrm{nmol} / 1$ (10-62).

Dynamic pituitary function tests revealed an adequate cortisol and growth hormone $(\mathrm{GH})$ response to glucagon stimulation with peak cortisol and GH concentrations of $680 \mathrm{nmol} / 1$ and $20.0 \mathrm{mIU} / 1$, respectively. A LH-releasing hormone(LHRH) stimulation test showed an impaired FSH response (baseline concentration $2.3 \mathrm{IU} / 1$ and peak concentration $4.0 \mathrm{IU} / 1)$. Thyrotropin-releasing hormone (TRH) test was also performed and sTSH was persistently less than $0.03 \mathrm{mIU} / 1$, consistent with thyrotoxicosis. Magnetic resonance imaging of the hypothalamic-pituitary region was normal.

$\mathrm{He}$ was treated with carbimazole using a dose-titration regime. Free $\mathrm{T}_{4}$ returned to normal after 2 months treatment and has remained in the normal range. The gynaecomastia showed gradual improvement after 3 months' treatment with carbimazole. However, the galactorrhoea persisted despite carbimazole, and the prolactin concentration remained in the range 1400-1800 mIU/1. Testosterone also remained low, range $2.3-8.7 \mathrm{nmol} / 1$. His sexual drive and impotence showed no improvement. Bromocriptine was therefore added to control the hyperprolactinaemia, whereupon the prolactin concentration fell to $80 \mathrm{mIU} / 1$ and testosterone increased to 13.8 $\mathrm{nmol} / \mathrm{l}$. His galactorrhoea resolved with restoration of normal sexual function.

Case 2

A 35-year-old Caucasian man presented with right-sided gynaecomastia for 3 months. He gave a history of lymphocytic lymphoma at the age of 16 years, which was treated by radiotherapy and surgery in Australia. The radiotherapy field included the groin region. Chemotherapy was not administered. Since that time, there had been no recurrence of the lymphoma. However, he had had bilateral hydroceles as a consequence of radiotherapy. Sexual drive and potency were normal. Physical examination showed the right testis to be diminished in size and there was marked lymphoedema of the left leg. Significant gynae- 
Table Sex hormone profile before and after treatment

\begin{tabular}{llll}
\hline & $\begin{array}{l}\text { Before } \\
\text { treatment }\end{array}$ & $\begin{array}{l}\text { After } \\
\text { treatment }\end{array}$ & $\begin{array}{l}\text { Normal } \\
\text { value }\end{array}$ \\
\hline Testosterone (nmol/l) & 46.5 & 10.2 & $10-30$ \\
Free testosterone (pmol/1) & 532 & 313 & $134-844$ \\
SHBG (nmol/l) & 122 & 19 & $10-62$ \\
\hline
\end{tabular}

comastia was confirmed on the right side while the left was normal. There was no galactorrhoea, visual field defect or loss of secondary sexual characteristics. Initial investigations showed elevation of FSH to 38.3 IU/1, but normal testosterone, prolactin, oestradiol and $\mathrm{LH}$ concentrations. His SHBG was $122 \mathrm{nmol} / \mathrm{l}$. Ultrasound confirmed a small right testis but the left testis was normal, and there was no evidence of recurrence of the lymphoma.

Two months later, he also developed left gynaecomastia. At this time, he reported a weight loss of $6 \mathrm{~kg}$, associated with palpitations and tremor. These symptoms had developed subsequent to the first visit. Physical examination revealed fine hand tremor, with a pulse rate of 96 beats/min and a small goitre. Thyroid hormone measurements confirmed thyrotoxicosis with $\mathrm{sTSH}<0.03 \mathrm{mIU} / 1$ and free $\mathrm{T}_{4}$ of $123 \mathrm{pmol} / 1$. He was treated with carbimazole. Within 2 months, his free $\mathrm{T}_{4}$ returned to normal and his gynaecomastia resolved completely. In parallel with these improvements, his testosterone and SHBG concentration also normalised with control of the thyrotoxicosis (table). The raised FSH concentration (48.7 IU/1) persisted after treatment, indicating the presence of subclinical hypogonadism independent of the thyroid status and presumably attributable to the previous radiotherapy for the lymphoma.

\section{Discussion}

In earlier reports, gynaecomastia was suggested to be a common manifestation of thyrotoxicosis, with a prevalence of $30-40 \%$. In the series of Becker et al, ${ }^{1}$ five of 12 male patients had gynaecomastia; while in the series of Ashkar et $a l^{2} 15$ of 40 had gynaecomastia. More recent studies have, however, suggested a weaker association. For example, Cheah showed that only one case out of 51 thyrotoxic men had gynaecomastia, ${ }^{3}$ while Tan et al reviewed 180 male thyrotoxic patients and none presented with gynaecomastia. ${ }^{5}$ The former two reports related to Caucasian patients, whereas the two more recent series related to Oriental patients. It should be noted that, in these four series, the presence of gynaecomastia was defined either by physical examination of consecutive patients or by review of case notes. Thus, variation in assignment is possible. Although there are ethnic differences between the early and recent series, differences in the definition and assignment of gynaecomastia are more likely to account for the observed differences. Cheah, however, deliberately looked for evidence of

\section{Learning point}

Gynaecomastia is an uncommon presenting feature of thyrotoxicosis in men. When it occurs, additional causes of hypogonadism should actively be sought

gynaecomastia in his thyrotoxic patients, and a discrepancy due to a low index of suspicion would not appear to be the case. ${ }^{3}$ Our local experience in Hong Kong also indicates that clinically apparent gynaecomastia is uncommon in Oriental thyrotoxic patients.

Gynaecomastia develops when there is an increase in the free oestrogen/androgen ratio. Progesterone may have an additive effect. Hyperprolactinaemia leads to galactorrhoea but does not usually have a direct effect on the development of gynaecomastia. ${ }^{67}$ In thyrotoxicosis, the typical changes in sex hormone profiles in men are raised total testosterone, SHBG, dihydrotestosterone, total oestradiol and $\mathrm{LH}^{8}{ }^{8-10}$ The increase in total testosterone can be accounted for by the increase in SHBG concentration. $^{8}{ }^{10}$ The concentrations of total and unbound oestradiol and LH are higher in subjects with gynaecomastia. While the increase in SHBG leads to a reduction in free testosterone, increased peripheral conversion of androgen to oestrogen appears to contribute to the high oestradiol concentration in hyperthyroidism. ${ }^{810}$ The gynaecomastia resolves after control of thyrotoxicosis, with reversion of histological changes. ${ }^{1}$

In our two patients, case 2 had a typical 'thyrotoxic' sex hormone profile with raised SHBG, and total testosterone at the time of presentation. However, subclinical hypogonadism was also documented before presentation of thyrotoxicosis. The hormonal profile in case 1 (low testosterone, impaired FSH and $\mathrm{LH}$ response to LHRH, and normal SHBG) is consistent with hyperprolactinaemia. However, the fact that gynaecomastia (but not galactorrhoea) subsided after control of thyrotoxicosis, but before commencement of bromocriptine, further supports the suggestion that thyrotoxicosis was responsible for the gynaecomastia. Both cases showed resolution of gynaecomastia after reversal of thyrotoxicosis. These two cases share one common feature, namely the presence of an additional insult apart from thyrotoxicosis. In case 1, hyperprolactinaemia causing hypogonadotrophic hypogonadism, was a major factor with superimposed (relatively mild) thyrotoxicosis precipitating the clinical presentation. In case 2 , the underlying pathology was (relatively mild) subclinical gonadal failure but the thyrotoxicosis was more severe.

We conclude that gynaecomastia is unusual as the initial feature of thyrotoxicosis. When it occurs, the possibility of additional underlying pathology should be considered. 
1 Becker KL, Winnacker JL, Matthews MJ, Higgins GA. Gynecomastia and hyperthyroidism. An endocrine and histological investigation. F Clin Endocrinol Metab 1968;28:277-85.

2 Ashkar FS, Smoak WM III, Gilson AJ, Miller R. Gynecomastia and mastoplasia in Graves' disease. Metabolism 1970;19:946-51.

3 Cheah JS.Gynaecomastia in hyperthyroidism. Singapore Med f 1971;12:241-3.

4 MuthusamyE. Hyperthyroidism with gynaecomastia, galactorrhoea and periodic paralysis. Singapore Med f 1991;32:371-2.

5 Tan TT, Ng ML, Wu LL, Khalid BA. Hyperthyroid Graves disease. A 5 year retrospective study. Med 7 Malaysia 1989 44:224-30.
6 Nomura K, Suzuki H, Saji M, et al. High serum progesterone in hyperthyroid men with Graves' disease. 7 Clin Endoone in hyperthyroid men with

7 Glass AR. Gynecomastia. Endocrinol Metab Clin North Am 1994;23:825-37.

8 Chopra IJ, Tulchinsky D. Status of estrogen-androgen balance in hyperthyroid men with Graves' disease. F Clin Endocrinol Metab 1974;38:269-77.

9 Kidd GS, Glass AR, Vigersky RA. The hypothalamicpituitary-testicular-axis in thyrotoxicosis. F Clin Endocrinol Metab 1979;48:798-802.

10 Chopra IJ. Gonadal steroids and gonadotrophins in hyperthyroidism. Med Clin North Am 1975;59:1109-21.

\title{
Lumbar hernia: a rare cause of large bowel obstruction
}

\author{
I G Hide, E E Pike, R Uberoi
}

\section{Summary}

We describe a 70-year-old woman presenting with large bowel obstruction secondary to incarceration of the mid descending colon within a lumbar hernia. This was diagnosed on barium enema and successfully treated surgically.

Keywords: hernia; intestinal obstruction; colon

Lumbar herniation occurs in the region of the flank bounded by the 12th rib, the iliac crest and the erector spinae and external oblique muscle groups. ${ }^{1}$ Herniation in this area is uncommon with fewer than 300 cases described in the literature. Strangulation is rare. ${ }^{2}$ We describe such a case presenting as distal large bowel obstruction.

\section{Case report}

A 70-year-old woman was admitted with a history of absolute constipation for one week, vomiting and vague lower abdominal pain. A long history of constipation was obtained and the patient reported taking several laxative preparations regularly. There was no history of weight loss. Previous operations included bilateral total hip replacements, appendicectomy and three Caesarean sections. The patient was obese with abdominal distension but no tenderness. No abnormality was found on palpation. Bowel sounds were active but not tinkling. No significant biochemical or haematological abnormalities were detected. An initial diagnosis of constipation with secondary obstruction was made. A plain abdominal film (figure 1) showed features of distal large bowel obstruction with no gas or faecal material seen in the sigmoid colon.

The patient was admitted and treated with suppositories and intravenous fluids and a nasogastric tube was inserted. An instant barium enema revealed sigmoid diverticular disease and a loop of mid descending colon lying lateral to the iliac crest. Both ends of the loop communicated with the remainder of descending colon and the appearances were consistent with a hernia through a narrow orifice (figure 2). A laparotomy was performed during which a moderate-sized hernia through the left inferior lumbar triangle was confirmed. This contained an incarcerated portion of descending colon. The bowel was reduced, found to be viable and the hernial orifice repaired. The patient recovered quickly and was discharged after 7 days.

\section{Discussion}

The lumbar region is anatomically defined superiorly by the lower border of the 12 th rib, inferiorly by the iliac crest, anterolaterally by the posterior border of the external oblique muscle,

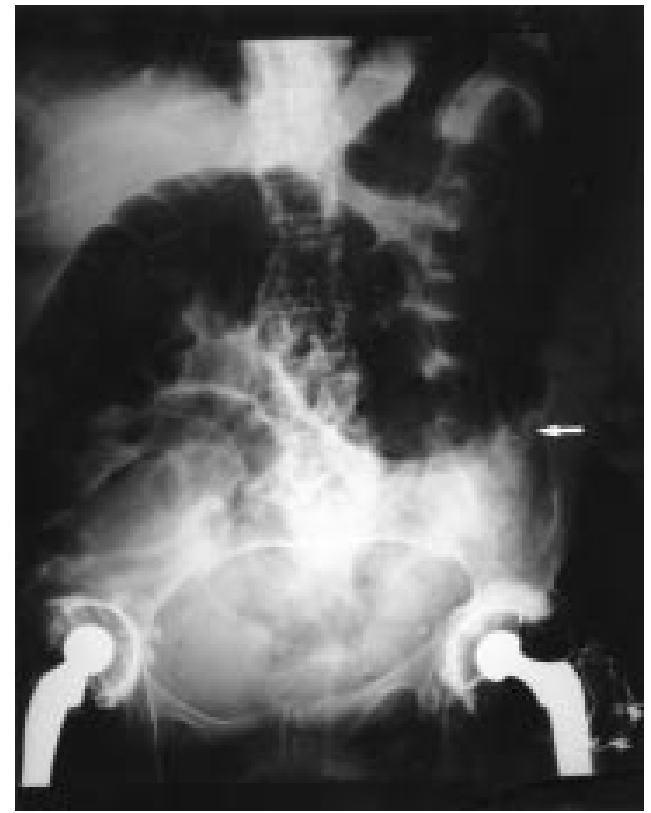

Figure 1 Plain abdominal X-ray demonstrating large bowel obstruction to the mid descending colon (white arrow) 


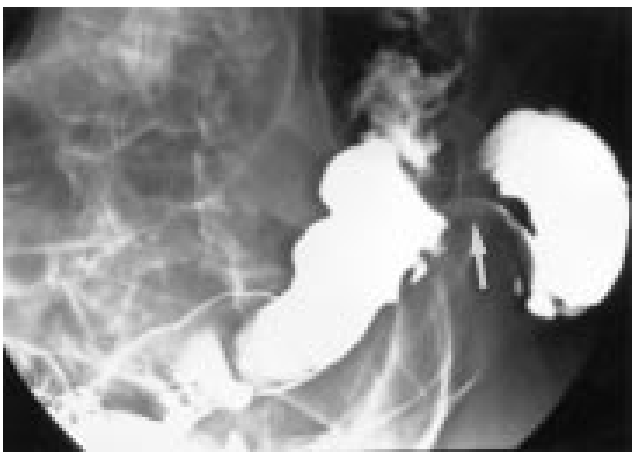

Figure 2 Single contrast barium enema demonstrating a short segment of herniated descending colon lying lateral to the iliac crest. Mucosal folds can be seen passing through the hernial orifice (white arrow)

and posteromedially by the erector spinae muscle group. Hernias can occur anywhere within the region but are most common through the superior lumbar triangle (of GrynfelttLesshaft), an inverted triangle bounded by 12 th rib, erector spinae and the posterior border of the internal oblique muscle. The inferior lumbar triangle (of Petit), bounded by iliac crest, posterior border of external oblique and the anterior border of latissimus dorsi is the next most frequent site. ${ }^{1}$ Herniation in the lumbar region is uncommon with fewer than 300 reported cases. It occurs more commonly in males (ratio 3:1) and is more frequent on the left than the right (ratio 2:1). Patients are usually between 50 and 70 years old. ${ }^{3}$ Lumbar hernias may be acquired $(80 \%)$ or congenital. If acquired, they may be spontaneous $(55 \%)$ or follow trauma, surgery or inflammation $(25 \%)$. Spontaneous herniation is usually the result of raised intra-abdominal pressure and an acquired predisposition such as muscle atrophy due to polio, obesity, old age or debilitating disease. ${ }^{4}$ The hernia may contain retroperitoneal fat, kidney, colon or less commonly small bowel, omentum, stomach, ovary, spleen or appendix. ${ }^{5}$ Patients are usually asymptomatic

1 Geis WP, Saletta JD. Lumbar hernia. In: Nyhus LM, Condon RE, eds, Hernia, 3rd edn. Philadelphia: Lippincott, 1989; pp 401-15.

2 Nyhus LM, Bombeck CT, Klein MS. Hernias. In: Sabiston DC, ed, Textbook of surgery, 14th edn. Philadelphia: Saunders, 1991; pp 1147

3 Baker ME, Weinerth JL, Andriani RT, et al. Lumbar hernia: diagnosis by CT. AfR 1987;148:565-7.

4 Horovitz IL, Schwarz HA, Dehan A A lumbar hernia presenting as an obstructing lesion of the colon. Dis Colon Rectum 1986;29:742-4.

\section{Learning points}

- lumbar hernias are rare defects in the posterolateral abdominal wall; they may contain fat, kidney, colon or even intraperitoneal structures, most commonly small bowel

- lumbar hernias are a rare cause of bowel obstruction due to incarceration or strangulation of bowel loops within the hernial sac

- lumbar hernias may be difficult to diagnose clinically, and imaging, particularly CT scanning, is helpful

but may complain of low back pain, colic or a pulling sensation. A soft, sometimes reducible mass may be palpable in the flank or bowel sounds audible if the hernia contains intestine. In obese patients detection of a mass is particularly difficult. Bowel incarceration occurs in $25 \%$ but because the hernial neck is generally wide, strangulation is said to be rare. ${ }^{2}$

Recent publications have stressed the role of computed tomography (CT) in the diagnosis of lumbar hernias and elegant demonstration of the anatomy can be obtained. ${ }^{367}$ Unfortunately, many patients have few or no signs to suggest the diagnosis and investigations will usually be tailored to clinical suspicion. In our case, clinical examination and plain abdominal films pointed to distal large bowel obstruction and the findings at barium enema were unexpected, though diagnostic. Lumbar hernias may be detected in this manner if the hernia contains colon but where the diagnosis is suspected, CT remains the investigation of choice as it will demonstrate the hernia regardless of the contents. Recently, reports of successful laparoscopic interventions have been published. ${ }^{8}$

Our case emphasises the clinical diagnostic difficulty posed by lumbar herniation and this condition should be borne in mind as a rare but eminently treatable cause of large bowel obstruction.

5 Thorek M. Lumbar hernia. F Int Coll Surg 1950;14:367-93. 6 Faro SH, Racette CD, Lally JF, et al. Traumatic lumbar hernia. $A f R$ 1990;154:757-9.

7 Lawdahl RB, Moss CN, Van Dyke JA. Inferior lumbar (Petit's) hernia. $A 7 R$ 1986;147:744-5.

8 Heniford BT, Iannitti DA, Gagner M. Laparoscopic inferior and superior lumbar hernia repair. Arch Surg 1997;132: 1141-4. 


\title{
Warfarin-induced skin necrosis
}

\author{
Andrew J Stewart, Ian D Penman, Margaret K Cook, Christopher A Ludlam
}

\begin{abstract}
Summary
Skin necrosis is a rare but serious sideeffect of treatment with warfarin. At particular risk are those with various thrombophilic abnormalities, especially when warfarinisation is undertaken rapidly with large loading doses of warfarin. With the increasing number of patients anticoagulated as out-patients for thromboprophylaxis, we are concerned that the incidence of skin necrosis may increase. If skin necrosis does occur, prompt remedial action may be of benefit in preventing permanent tissue damage.
\end{abstract}

Keywords: warfarin; skin necrosis; protein C; antiphospholipid antibody; adverse drug reaction

Warfarin-induced skin necrosis (WISN) is an uncommon, catastrophic complication of oral anticoagulant therapy. ${ }^{1}$ A substantial minority of cases occur in association with a familial deficiency of protein $\mathrm{C}^{2}$ or protein $\mathrm{S}^{3} \mathrm{An}$ acquired deficiency of protein $\mathrm{S}$ secondary to the development of antiphospholipid antibodies has also been implicated. ${ }^{4}{ }^{5}$ We present three cases of WISN, in two of whom antiphospholipid antibodies were the only identifiable predisposing factor. Neither of these two cases had a low protein $\mathrm{C}$ or $\mathrm{S}$.

\section{Case reports}

Case 1

A 39-year-old woman with no personal or family history of thromboembolic disease suffered a deep vein thrombosis (DVT), confirmed by venography. Treatment was begun with intravenous unfractionated heparin which was continued for 2 days, after which she discharged herself from hospital.

One week later, she was re-admitted with clinical evidence of a pulmonary embolism. Intravenous unfractionated heparin was restarted and warfarin (two doses of $10 \mathrm{mg}$ and one of $5 \mathrm{mg}$ on three consecutive days) was commenced simultaneously. Heparin was discontinued on the third day, when the INR reached 2.3. That evening, she developed extremely painful ecchymotic lesions on both lower limbs. Initially, it was felt that these were haematomas, but over the next 12 hours it became clear that skin necrosis was developing. Despite re-heparinisation and treatment with fresh frozen plasma and intravenous vitamin $\mathrm{K}$, she sustained extensive necrosis of the skin of both legs (figure). She was eventually discharged from hospital 3 months later, after skin grafting. Testing for thrombophilia (table) revealed a lupus anticoagulant and high-titre IgG anticardiolipin antibodies.

\section{Case 2}

A 32-year-old woman had a history of venographically proven puerperal DVT, following which she was anticoagulated with warfarin for about 6 months without complication. Eight years later, she had a second pregnancy. Thromboprophylaxis with subcutaneous unfractionated heparin was begun immediately after delivery. One week later, she developed clinical evidence of a DVT and was warfarinised with simultaneous discontinuation of heparin. Three days after this, a painful 'bruise' appeared on her left thigh, which she had banged on a table. The skin in the centre of the affected area progressed to frank necrosis over the following 48 hours. Warfarin was discontinued, but no other treatment was given. Healing was slow and she required surgical debridement after 7 weeks.

One week after the debridement, she sustained a pulmonary embolism and received intravenous unfractionated heparin. After 48

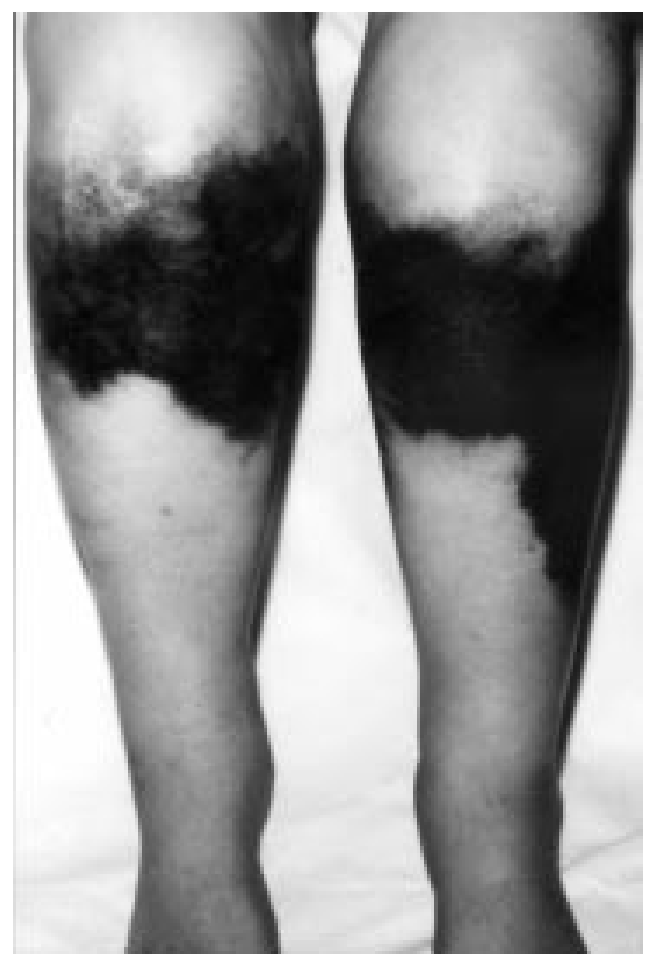

Figure Warfarin-induced skin necrosis affecting both legs 
Table Investigations for thrombophilia. Cases 1 and 2 had evidence of lupus anticoagulant, as demonstrated by a prolonged dilute Russell's viper venom time (DRVVT) which corrected on the addition of platelet phospholipid (DRVVT(PN)). Case $1 \mathrm{had}$, in addition, raised IgG anticardiolipin antibodies and case 3 a reduction in free protein $\mathrm{S}$. APCR = activated protein $\mathrm{C}$ resistance.

\begin{tabular}{lcccc}
\hline & Case 1 & Case 2 & Case 3 & Normal range \\
\hline Protein C (IU/ml) & 0.96 & 1.00 & 1.37 & $0.67-1.38$ \\
Protein S antigen, total (IU/ml) & 1.02 & 1.32 & 0.81 & $0.64-1.54$ \\
Protein S antigen, free (IU/ml) & 0.71 & 1.34 & 0.55 & $0.61-1.43$ \\
Antithrombin (IU/ml) & 0.89 & 1.02 & 0.92 & $0.80-1.20$ \\
Anticardiolipin IgG $(\mathrm{g} / \mathrm{l})$ & 55.4 & 1.9 & $<5.0$ & $<8.0$ \\
Anticardiolipin IgM $(\mathrm{mg} / \mathrm{l})$ & 0 & 0.2 & 8.3 & $<11.0$ \\
DRVVT ratio & 1.24 & 1.13 & 0.86 & $0.90-1.09$ \\
DRVVT(PN) ratio & 1.12 & 1.03 & & $<1.10$ \\
Kaolin clotting time ratio & 0.8 & 1.04 & 1.03 & $<2.0$ \\
APCR & 2.6 & $>3.6$ & not done & $>2.0$ \\
Factor V Leiden & negative & negative & negative & negative \\
\hline
\end{tabular}

hours, warfarin was re-introduced (10 mg daily for 3 days and $5 \mathrm{mg}$ on the fourth day). During the period of warfarinisation, her activated partial thromboplastin time remained within the therapeutic range. On the fourth day of warfarin therapy, when her INR was 5.2, she developed a well-circumscribed ecchymosis around the scar from her recent debridement and a similar lesion on her left calf. There was no history of trauma on this occasion. An ultrasound scan showed no haematoma. After 24 hours, the central area of the ecchymosis had become necrotic. Warfarin was discontinued. Over the next day, the extent of the necrotic skin did not increase and there was some improvement in the appearance of her leg. It was considered important to continue anticoagulation, and warfarin was cautiously reintroduced when the INR had fallen to 2.7, and was continued for 5 months. During this time, there was substantial healing of the affected areas, but a residual necrotic area eventually required surgical excision. Investigation revealed the presence of a lupus anticoagulant.

Case 3

A 26-year-old woman, with a history of pulmonary embolism on two occasions, was converted from warfarin to subcutaneous low molecular weight heparin and aspirin when she became pregnant. Investigations for thrombophilia had shown only a borderline deficiency of free protein S (table). She was delivered at 28 weeks' gestation by Caesarean section because of foetal distress. After delivery, heparin was continued and warfarin restarted. On the seventh postoperative day, when her INR was 3.1, she developed an area of extremely tender erythema on her left calf, surrounded by bruising. This was recognised as early skin necrosis and she was immediately treated with intravenous unfractionated heparin, vitamin $\mathrm{K}$ and fresh frozen plasma. Therapeutic heparinisation, initially with unfractionated, then with low molecular weight heparin was continued for two weeks, during which time her calf began to heal. Because of the strong history of venous thromboembolic disease, warfarin was re-introduced 15 days after the appearance of early necrosis. A daily dose of $3 \mathrm{mg}$ was given with continuation of heparin until her INR was within the target

\section{Learning points}

- antiphospholipid antibodies can predispose to the development of WISN

- large swings in INR should be avoided during initiation of warfarin, especially in patients at risk of WISN and in those not receiving heparin

- early diagnosis and treatment of WISN lessens the risk of permanent tissue damage, and early WISN must be distinguished from haematoma formation

range. Eleven days after warfarin was restarted her INR was 3.8 and heparin was discontinued. Her calf healed with no permanent skin damage.

\section{Discussion}

When warfarin therapy is started, there is a more rapid fall in the concentration of protein $\mathrm{C}$ than of the other vitamin-K-dependent procoagulant factors. The temporary hypercoagulable state which results is believed to lead to the development of WISN in susceptible individuals. The use of large loading doses of warfarin may exacerbate this effect and may have contributed to the development of WISN in case 2. Particularly at risk are those with an inherited deficiency of protein $\mathrm{C}^{2}$ or other impairment of the protein C pathway. ${ }^{67}$ There is in vitro evidence that an acquired deficiency of protein $\mathrm{C}$ or $\mathrm{S}$ may result from their inhibition by antiphospholipid antibodies. ${ }^{8}$ This might be a mechanism whereby antiphospholipid antibodies could predispose to WISN, although other mechanisms must also be operational to explain the occurrence of WISN without concomitant detectable protein $\mathrm{C}$ or S deficiency in our first two patients.

A consequence of the growth in the number of indications for warfarin therapy is that many patients are started on warfarin as out-patients. Protocols for the commencement of warfarin such as that of Fennerty et $a l^{9}$ aim to achieve a therapeutic INR within 3-4 days and were written for the treatment of acute thromboembolism, rather than for prophylaxis. We are concerned that such rapid warfarinisation in the out-patient setting without concomitant heparinisation may put some patients, such as those with undetected thrombophilic abnormalities, at risk of WISN. We agree with the suggestion ${ }^{10}$ that a more gradual approach, using low-dose warfarin and aiming to achieve a therapeutic INR in 10-12 days would lessen this risk without compromising the treatment of patients who are being electively anticoagulated. Patients known to be at risk of WISN (those with a previous episode, protein C or S deficiency and, our data suggest, antiphospholipid antibodies) should also be warfarinised in this gradual way, and consideration should be given in their case to therapeutic anticoagulation with heparin from the time of commencement of the warfarin until the achievement of an INR within the target range. 
Our third case demonstrates that, if WISN does occur, prompt initiation of remedial therapy may prevent the development of permanent tissue damage. Initial appearances

1 Eby CS. Warfarin-induced skin necrosis. Hematol Oncol Clin North Am 1993;7:1291-301.

2 McGehee WG, Klotz TA, Epstein DJ, Rapaport SI Coumarin necrosis associated with hereditary protein $\mathrm{C}$ deficiency. Ann Intern Med 1984;101:59-60.

3 Grimaudo V, Gueissaz F, Hauert T, Sarraj A, Kruithof E Bachmann F. Necrosis of the skin induced by coumarin in patient deficient in protein S. BMF 1989;298:233-4.

4 Moreb J, Kitchens CS. Acquired functional protein S deficiency, cerebral venous thrombosis, and coumarin skin report of two cases. Am f Med 1989;87:207-10.

5 Wattiaux M-J, Herve R, Robert A, Cabane J, Housset B, Imbert J-C. Coumarin-induced skin necrosis associated with acquired protein $S$ deficiency and antiphospholipid with acquired protein $S$ deficiency and antiphospholip
antibody syndrome. Arthritis Rheum 1994;37:1096-100. may mimic those of a haematoma (a much more common complication of warfarin therapy) and a high index of suspicion is needed.

6 Dahlbäck B. Protein S and C4b binding protein: components involved in the regulation of the protein $\mathrm{C}$ anticoagulant system. Thromb Haemost 1991;66:49-61.

7 Makris M, Bardhan G, Preston FE. Warfarin induced skin necrosis associated with activated protein $\mathrm{C}$ resistance (letter). Thromb Haemost 1996;75:523-4.

8 Malia RG, Kitchen S, Greaves M, Preston FE. Inhibition of activated protein $\mathrm{C}$ and its cofactor protein $\mathrm{S}$ by antiphospholipid antibody. Br f Haematol 1990;76:101-7.

9 Fennerty A, Campbell IA, Routledge PA. Anticoagulants in venous thromboembolism. Guidelines for optimum treatment. BMF 1988;297:1285-8.

10 Enzenauer RJ, Berenberg JL, Campbell J. Progressive warfarin anticoagulation in protein $\mathrm{C}$ deficiency: a therapeutic strategy. Am F Med 1990;88:697-8.

\title{
Calcium-channel blockade can mask the diagnosis of Conn's syndrome
}

\author{
Morris J Brown, Ruth V Hopper
}

Clinical Pharmacology

Unit, University of

Cambridge, Box 110

Addenbrookes

Hospital, Cambridge

CB2 2QQ, UK

M J Brown

R V Hopper

Accepted 22 October 1999

\section{Summary}

A 30-year-old woman presented with hypertension and hypokalaemia, and was found to have primary aldosteronism due to a Conn's adenoma, whose removal cured the hypertension. Before surgery, the characteristic biochemical changes which enabled the diagnosis were completely masked by administration of a calcium-channel blocker, amlodipine. It is likely that widespread use of this class of drugs contributes to under-diagnosis of Conn's syndrome as a curable cause of hypertension.

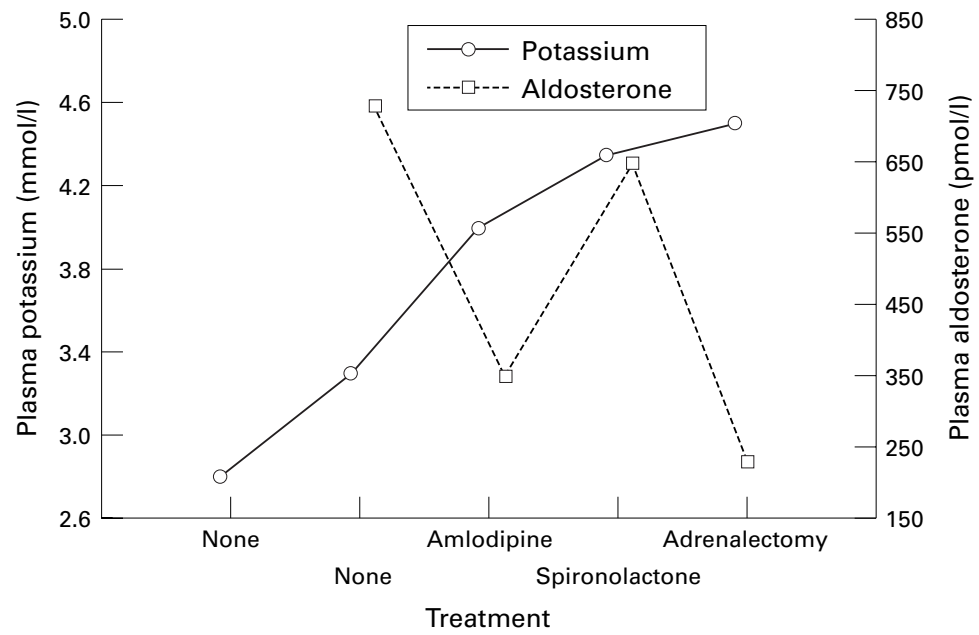

Figure Effects of treatment on plasma $\mathrm{K}^{+}$and aldosterone levels in a patient with Conn's syndrome. Plasma $\mathrm{K}^{+}(\mathrm{o}-\mathrm{o}$, left axis) and aldosterone ( - - - , right axis) were measured before any treatment, and 4 weeks after the drug or surgical interventions shown on the $\mathrm{x}$-axis.
Keywords: Conn's syndrome; aldosterone; calcium blockade

Since its first recognition, the prevalence of primary hyperaldosteronism, or Conn's syndrome, as a cause of hypertension has been disputed. Initial optimism that $20 \%$ of hypertensives may have a curable cause gave way to a realisation that many patients with essential hypertension have low renin hypertension, and nowadays less than $1 \%$ of patients started on treatment for hypertension are considered to have the diagnosis. Recently, systematic surveys using a ratio of aldosterone to renin above 800 as an upper limit of normal have suggested prevalence figures greater than $10 \%$ (of hypertensives). ${ }^{1}$ Ironically, changes in modern pharmacological treatment of hypertension have probably reduced the sensitivity of plasma electrolyte measurements for detection of Conn's syndrome, since the 4-8-fold lower doses of diuretics - and lower overall use of this class - than in Conn's time means that plasma $\mathrm{K}^{+}$values $<3 \mathrm{mmol} / \mathrm{l}$ are seen infrequently; it is also likely that reductions in average salt intake limit the degree of hypokalaemia in Conn's syndrome. Both sodium and diuretic intake influence how much $\mathrm{K}^{+}$is lost through $\mathrm{K}^{+} / \mathrm{Na}^{+}$ exchange in the renal distal tubule. Angiotensin-converting enzyme (ACE) inhibitors suppress angiotensin-II-mediated aldosterone secretion. Suppression of aldosterone release from adrenal zona glomerulosa cells by $\mathrm{Ca}^{++}$entry blockers is well described, ${ }^{23}$ but their effect in Conn's syndrome has been controversial. ${ }^{45}$ While the specific antagonist for aldosterone, spironolactone, is known sometimes to confuse diagnosis of an adenoma 
by masking suppression of the contralateral adrenal, there is no generally recognised recommendation to withdraw $\mathrm{Ca}^{++}$blockers during investigation of possible Conn's syndrome; there is also no published experience with amlodipine, arguably the most powerful and now most widely used member of the class in hypertension. We therefore report here a patient with a Conn's adenoma in whom serial $\mathrm{K}^{+}$and aldosterone measurements demonstrated how treatment with amlodipine can completely mask the diagnosis.

A previously asymptomatic 30-year-old doctor's wife was found to have a blood pressure of $160 / 110 \mathrm{mmHg}$ at her general practice new patient medical. Plasma electrolytes showed a $\mathrm{Na}^{+}$of 144 and $\mathrm{K}^{+}$of $2.8 \mathrm{mmol} / \mathrm{l}$, and the patient was referred untreated for further investigation. A low plasma renin $(<0.2 \mathrm{pmol} /$ $\mathrm{ml} / \mathrm{h}$ ) and elevated plasma aldosterone (730 pmol/l) suggested a diagnosis of Conn's syndrome. Onset of early morning headaches necessitated some antihypertensive treatment, and the patient was started on amlodipine $5 \mathrm{mg}$ daily since premature use of spironolactone can confuse tests to distinguish adenomas from bilateral hyperplasia. Two weeks later, blood pressure had fallen to $110 / 70 \mathrm{mmHg}$, and the diagnosis of a right adrenal adenoma was made by computed tomography (CT) scan, and unilateral increased uptake of selenium cholestenol by the right adrenal on scintiscan. At this stage, treatment was changed from amlodipine to spironolactone, with continued excellent blood pressure control. A $2 \times 1 \mathrm{~cm}$ adrenal adenoma was removed one month later.

The figure shows the changes in plasma $\mathrm{K}^{+}$ and aldosterone in response to each change in treatment. At least two $\mathrm{K}^{+}$measurements were made during each phase, with all the pairs being similar except for the spontaneous variation in $\mathrm{K}^{+}$before treatment was started. Unexpectedly, plasma $\mathrm{K}^{+}$was $>4.0 \mathrm{mmol} / 1$ on each occasion after introduction of amlodipine, almost certainly due to a suppression of aldosterone secretion. Indeed the fall in plasma aldosterone is all the more impressive in that a

1 Gordon RD, Ziesak MD, Tunny TJ, Stowasser M, Klemm SA. Evidence that primary aldosteronism may not be uncommon: $12 \%$ incidence among antihypertensive drug trial volunteers. Clin Exp Pharmacol Physiol 1993;20:296-8.

2 Aguilera G, Catt KJ. Participation of voltage-dependent calcium channels in the regulation of adrenal glomerulosa function by angiotensin II and potassium. Endocrinology 1986;118:112-8.

3 Opocher G, Rocco S, Murgia A, Mantero F. Effect of verapamil on aldosterone secretion in primary aldosteronism. $\mathcal{F}$ Endocrinol Invest 1987;10:491-4.

\section{Learning points}

- the diagnosis of Conn's syndrome should be suspected in any hypertensive patient with a plasma $\mathrm{Na}^{+}>140 \mathrm{mmol} / \mathrm{l}$, whose plasma $\mathrm{K}^{+}$is below the local laboratory's normal range

- the diagnosis of Conn's syndrome is then readily confirmed by demonstration of an elevated aldosterone to renin ratio (usually $>800$ )

- administration of a calcium channel blocker, now estimated to be part of the treatment of $25 \%$ of hypertensive patients, can completely suppress both the elevated aldosterone secretion and consequent hypokalaemia. Therefore, the diagnosis of Conn's syndrome may be neither suspected or confirmed in such patients

rise in plasma $\mathrm{K}^{+}$usually stimulates aldosterone secretion.

\section{Discussion}

The diagnosis of Conn's syndrome in this patient was easy because of the prompt initial measurement of electrolytes by the general practitioner. The figure shows how the subsequent rise in plasma $\mathrm{K}^{+}$, due first probably to spontaneous variation in tumour secretion of aldosterone, and then to suppression of $\mathrm{Ca}^{++}-$ dependent secretion, caused the typical changes to be diminished and then masked altogether. During further research, we found that 1049 out of 6211 treated hypertensives $(17 \%)$ now receive a $\mathrm{Ca}^{++}$-blocker. Definitive conclusions from one case are unwise, and a formal prevalence study of Conn's syndrome in primary care seems overdue. Meanwhile we reiterate the importance of plasma electrolyte measurement before starting therapy, and recommend consideration of the diagnosis in any patient with plasma $\mathrm{Na}^{+}$and $\mathrm{K}^{+}$in the upper and lower parts of their range, respectively, prior to $\mathrm{Ca}^{++}$-channel blockade.

4 Leonetti G, Terzoli L, Zanchetti A. Calcium antagonists and responsiveness of the adrenal glands to aldosteronereleasing stimuli in hypertensive patients. F Hypertens 1987; 5(suppl):S119-22.

5 Nadler JL, Hsueh W, Horton R. Therapeutic effect of calcium channel blockade in primary aldosteronism. $\mathcal{f}$ Clin Endocrinol Metab 1985;60:896-9. 